\title{
A national database propensity score-matched comparison of minimally invasive and open colectomy for long-term opioid use
}

\author{
Amir L. Bastawrous ${ }^{1} \cdot$ Kara K. Brockhaus ${ }^{2} \cdot$ Melissa I. Chang ${ }^{3} \cdot$ Gediwon Milky $^{4,5} \cdot$ I.-Fan Shih ${ }^{4} \cdot$ Yanli Li ${ }^{4}$. \\ Robert K. Cleary ${ }^{3}{ }^{\circ}$
}

Received: 3 September 2020 / Accepted: 21 January 2021 / Published online: 10 February 2021

(C) The Author(s) 2021

\begin{abstract}
Background Opioid dependence is a public health crisis and surgery is a risk factor for long-term opioid use. Though minimally invasive surgery (MIS) is associated with less perioperative pain, demonstrating an association with less long-term opioid use would be another reason to justify adoption of minimally invasive techniques. We compared the rates for long-term opioid prescriptions among patients in a large national database who underwent minimally invasive and open colectomy. Methods Using the MarketScan Database, we retrospectively analyzed patients undergoing colon resection for benign and malignant diseases between 2013 and 2017. Among opioid-naïve patients who had $\geq 1$ opioid prescriptions filled perioperatively (30 days before surgery to 14 days after discharge), propensity score matching was applied for group comparisons [open (OS) versus MIS, and laparoscopic (LS) versus robotic-assisted surgery (RS)]. The primary outcome was long-term opioid use defined as the proportion of patients with $\geq 1$ long-term opioid prescriptions filled 90-180 days after discharge. Risks factors for long-term opioid use were assessed using logistic regression.

Results Among the 5413 matched pairs in the MIS versus OS cohorts, MIS significantly reduced long-term opioid use of 'any opioids' (13.3\% vs. $20.9 \%$ ), schedule II/III opioids ( $11.7 \%$ vs. $19.2 \%$ ), and high-dose opioids ( $4.3 \%$ vs. $7.7 \%$; all $p<0.001$ ). Among the 1195 matched pairs in the RS versus LS cohorts, RS was associated with less high-dose opioids (2.1\% vs. 3.8\%, $p=0.015$ ) 90-180 days after discharge. Other risk factors for long-term opioid use included younger age, benign indications, tobacco use, mental health conditions, and $>6$ Charlson comorbidities.

Conclusion Minimally invasive colectomy is associated with a significant reduction in long-term opioid use when compared to OS. Robotic-assisted colectomy was associated with less high-dose opioids compared to LS. Increasing adoption of minimally invasive surgery for colectomy and including RS, where appropriate, may decrease long-term opioid use.
\end{abstract}

Keywords Colon resection $\cdot$ Opioid $\cdot$ Minimally invasive $\cdot$ Robotic-assisted surgery $\cdot$ Laparoscopic surgery

Opioid dependence and overdose have recently attracted public awareness and concern as a public health problem.

Robert K. Cleary

Robert.Cleary@stjoeshealth.org

1 Swedish Cancer Institute, Seattle, WA, USA

2 Inpatient Pharmacy, St. Joseph Mercy Hospital Ann Arbor, Ann Arbor, MI, USA

3 Department of Surgery, St. Joseph Mercy Hospital Ann Arbor, 5325 Elliott Dr. Suite 104, Ann Arbor, MI 48106,, USA

4 Global Health Economics and Outcomes Research, Intuitive Surgical, Inc., Sunnyvale, CA, USA

5 Department of Pharmacy Practice, Purdue University, West Lafayette, IN, USA
In 2017, opioids caused 14.9 overdose deaths per 100,000 United States (US) population. Of these, prescription opioids were associated with 5.2 overdose deaths per 100,000 US population [1]. The US societal economic burden of prescription opioid overdose, abuse and dependence is estimated to be $\$ 78.5$ billion annually [2].

Short-term opioid use for management of postoperative pain is an important risk factor for long-term opioid use and dependence in major and minor surgeries [3]. A database analysis of seven surgical procedures showed that the proportion of new persistent opioid users was highest among patients who had colectomy (17\%), followed by patients who had total knee replacement (15.2\%) [4]. If minimally invasive surgery (MIS) is associated with less long-term opioid use than open surgery, then increasing minimally invasive 
colectomy training efforts and adoption would be quality improvement. The role for the robotic-assisted approach as a minimally invasive option in reducing long-term opioid use is also an unanswered question. Previous studies reported that robotic-assisted surgery is associated with reduced postoperative pain $[5,6]$. However, there is limited literature examining the potential benefit of the robotic approach in reducing short-term and long-term opioid use [7, 8], particularly for colectomies.

Using population-based insurance claims data, we aimed to evaluate long-term opioid use after colon resections and compare them by surgical approach. We hypothesized that (1) patients undergoing minimally invasive colon resection are less likely to fill long-term opioid prescriptions postoperatively compared to open surgery (OS) and (2) among MIS options, the robotic-assisted (RS) approach is associated with fewer opioid prescriptions filled than laparoscopic colectomy (LS).

\section{Materials and methods}

The manuscript was prepared in accordance with the STROBE (STrengthening the Reporting of OBservational studies in Epidemiology) guideline for reporting observational cohort study.

\section{Data sources and study sample}

This is a retrospective claims data analysis using the IBM® MarketScan ${ }^{\circledR}$ Research Database (MarketScan), a large dataset capturing linked and de-identified inpatient, outpatient and pharmacy services from a range of employer-provided health insurance companies [9]. The annual medical database report contains more than 40 million beneficiaries from approximately 350 payers in the US [9]. As an aggregated, de-identified, Health Insurance
Portability and Accountability Act (HIPAA)-compliant database, retrospective analyses of MarketScan are considered exempt from informed consent and institutional review board approval.

The study population consisted of patients aged 18 years or older who underwent colon resection between 2013 and 2017. Procedures included sigmoidectomy and left or right hemicolectomy for benign and malignant indications. We used International Classification of Diseases and Related Health Problems, Ninth Revision (ICD-9) and Tenth Revision (ICD-10) codes to define the eligible colon resection cases and differentiate surgical approaches (Supplementary Table 1). For this study, eligible patients were those who did not fill an opioid prescription 30-180 days before surgery (opioid-naïve) and had at least one opioid prescription filled perioperatively (30 days before surgery to 14 days after discharge; Fig. 1). Patients receiving opioids within 30 days of surgery included prescriptions provided preoperatively for postoperative pain control. Inclusion of these patients as opioid-naïve is consistent with prior studies [1].

Because the dataset does not contain inpatient opioid use, we included only patients who had at least one opioid prescription filled perioperatively to capture all patients exposed to opioids after surgery. Study patients were required to be continuously enrolled with medical and pharmacy benefit coverage 180 days before to 180 days after colon resection to capture baseline comorbidities and evaluate complete health services utilization. We excluded patients who were opioid tolerant (defined as having opioid prescriptions filled between 30 and 180 days before admission for surgery), patients with an opioid use disorder or chronic pain diagnosis prior to surgery, patients with a prolonged hospital length of stay (LOS > 14 days; a surrogate for emergent or more complicated cases), multiple colon resections, any hospitalizations during the follow-up period, and patients with invalid opioid prescription data.

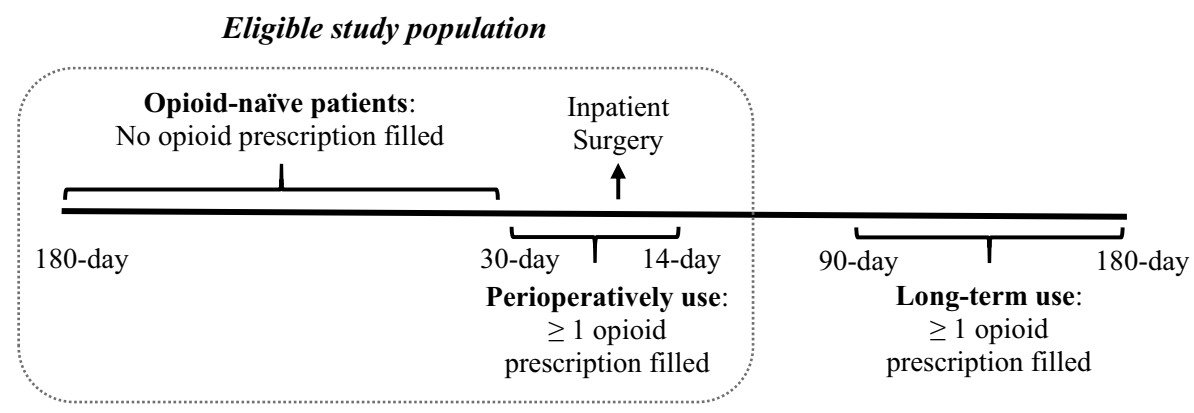

Fig. 1 Study criteria and outcomes definition. Patients were included if they did not fill an opioid prescription 180 days before surgery (opioid-naïve) and had at least 1 opioid prescription filled 30 days before surgery to 14 days after discharge (perioperative use). The out- come of long-term opioid use was defined as at least 1 opioid prescription filled between 90 and 180 days after discharge; prolonged use was defined as 1 or more additional opioid prescription(s) filled between 180 and 365 days after discharge 


\section{Exposure variables}

We identified surgical modality using ICD-9 and ICD-10 codes (Supplementary Table 1) and classified patients into OS, LS or RS groups. In the evaluation of MIS versus OS, LS and RS were merged into the MIS group.

\section{Outcome variables}

Opioid prescriptions filled were identified using MarketScan pharmacy claims data. Perioperative opioid prescriptions were defined as any outpatient filled prescriptions from 30 days before admission to 14 days after discharge. Longterm opioid prescriptions were defined as at least 1 opioid prescription filled between 90 and 180 days after discharge. These definitions are consistent with prior studies and represent time frames in which uncomplicated postoperative recovery would be expected following colon surgery [3, 10]. For patients filling at least 1 opioid prescription perioperatively, we calculated the proportion of long-term opioid use (i.e., patients with $\geq 1$ long-term opioid prescriptions filled 90-180 days after discharge) and categorized opioids as (1) 'any opioids' [obtained using the national drug code and linking the Marketscan drug claim data to a Center for Disease Control (CDC) opioids table], (2) controlled substance schedule II or III opioids [Schedule II or III opioids by Drug Enforcement Administration (DEA) classification in Marketscan dataset: https://www.dea.gov/drug-scheduling], and (3) high-dose opioids ( $\geq 50$ Morphine Milligram Equivalents per day calculated based on prescriptions and analogous to morphine $7.5 \mathrm{mg} \mathrm{q} 4$ hours or oxycodone $5 \mathrm{mg} \mathrm{q} 4$ hours).

\section{Patient factors}

Baseline sociodemographic and clinical characteristics included as potential confounders were age, sex, region, residential area metropolitan status, annual income level, insurance plan, year of surgery, presence of colorectal cancer and Charlson Comorbidity Index (CCI) scores. Insurance plans were classified into preferred provider organization (PPO), comprehensive insurance, health maintenance organization (HMO), point-of-service (POS) and other insurance plans. Using ICD-9/ICD-10 diagnosis codes, conditions known to increase the risk of opioid overuse were identified based on existing literature. These conditions were tobacco abuse or history, alcohol abuse or dependence, and mental health conditions (schizophrenia, mood disorders, anxiety, dissociative and somatoform problems, or depression) [10, 11]. Patient comorbidities and the above risk factors were evaluated at the index hospitalization and in the 180-day preoperative period.

\section{Statistical analysis}

Propensity score matching (PSM) was used to balance baseline sociodemographic and clinical characteristics when comparing opioid prescriptions by surgical modality (MIS vs. OS and RS vs. LS). All patient factors described above and shown in Table 1 were included as covariates in the model performed to generate the propensity score based on prior studies and clinical relevance $[3,10,11]$. A separate category for "unknown" was created for infrequent variables with missing values. We used a logistic regression model to calculate the propensity scores that estimated the likelihood that a patient would receive either MIS versus OS or RS versus LS [12]. Then, 1:1 propensity score matching using a 5-to-1 digits greedy matching without replacement technique was used to create matched samples for analysis [13]. A standardized difference of $<0.1$ was used to assess covariates balance achieved between the matched samples. Within each matched sample, logistic regression was used to assess the effect of the surgical approach on opioid prescriptions; covariates that were imbalanced after PSM were additionally adjusted in the regression model [14]. Odds ratios (OR) were calculated for opioid outcomes and considered statistically significant if the $95 \%$ confidence interval (CI) excludes the null value. In subgroup analyses, we separated malignant and non-malignant patients based on presence of diagnosis codes of colorectal cancer and repeated all analyses above respectively. Multivariate logistic regression was performed to assess risk factors for long-term opioid use. To understand the impact of LOS on opioid prescription fills, percentages of patients who filled any opioids were plotted based on colon resection inpatient $\operatorname{LOS}(\leq 3,4,5,6, \geq 7$ days) as sensitivity analysis. All analyses were conducted using SAS version 9.4 (SAS Institute, Cary, NC, USA).

\section{Results}

There were 34,368 continuously enrolled patients who underwent colon resection between 2013 and 2017 . After excluding patients with prolonged inpatient LOS (>14-day), chronic pain, multiple colon resections, any hospitalizations during 180-day follow-up, invalid opioid prescription data, and opioid prescriptions filled preoperatively (180-30 days before surgery), there were 20,638 opioid-naïve patients (Fig. 2). We further excluded 5751 patients (27.9\%) who did not fill opioids perioperatively, and the final cohort consisted of 14,887 eligible patients for long-term use assessment: 5663 patients (38.0\%) had OS, 8055 (54.1\%) had LS and 1169 (7.9\%) underwent RS. The distribution of benign and malignant disease was $39.2 \%$ malignant, $17.6 \%$ benign neoplasia, $29.4 \%$ diverticulitis, 5.5\% inflammatory bowel disease, and $8.3 \%$ 
Table 1 Baseline sociodemographic characteristics before and after propensity score matching

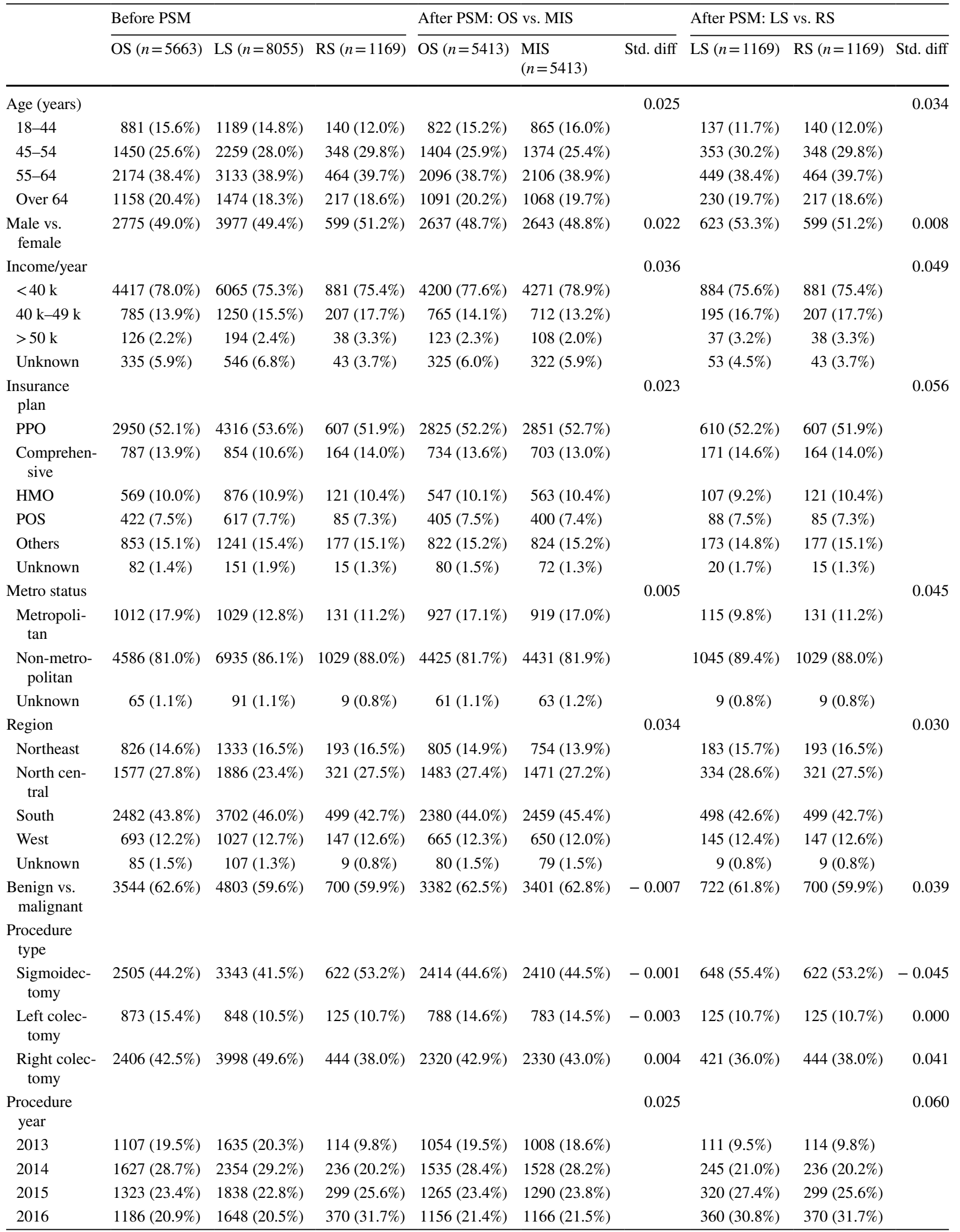


Table 1 (continued)

\begin{tabular}{|c|c|c|c|c|c|c|c|c|c|}
\hline & \multicolumn{3}{|l|}{ Before PSM } & \multicolumn{3}{|c|}{ After PSM: OS vs. MIS } & \multicolumn{3}{|c|}{ After PSM: LS vs. RS } \\
\hline & OS $(n=5663)$ & $\mathrm{LS}(n=8055)$ & $\operatorname{RS}(n=1169)$ & OS $(n=5413)$ & $\begin{array}{l}\text { MIS } \\
(n=5413)\end{array}$ & Std. diff & $\operatorname{LS}(n=1169)$ & $\operatorname{RS}(n=1169)$ & Std. diff \\
\hline 2017 & $420(7.4 \%)$ & $580(7.2 \%)$ & $150(12.8 \%)$ & $403(7.4 \%)$ & $421(7.8 \%)$ & & $133(11.4 \%)$ & $150(12.8 \%)$ & \\
\hline $\begin{array}{l}\text { Tobacco } \\
\text { abuse/Hx }\end{array}$ & $948(16.7 \%)$ & $1300(16.1 \%)$ & $208(17.8 \%)$ & $891(16.5 \%)$ & $857(15.8 \%)$ & -0.017 & $199(17.0 \%)$ & $208(17.8 \%)$ & 0.020 \\
\hline $\begin{array}{c}\text { Alcohol } \\
\text { abuse/ } \\
\text { depend }\end{array}$ & $144(2.5 \%)$ & $148(1.8 \%)$ & $15(1.3 \%)$ & $130(2.4 \%)$ & $130(2.4 \%)$ & 0.000 & $13(1.1 \%)$ & $15(1.3 \%)$ & 0.016 \\
\hline $\begin{array}{l}\text { Mental health } \\
\text { cond. }\end{array}$ & $1043(18.4 \%)$ & $1405(17.4 \%)$ & $233(19.9 \%)$ & $1000(18.5 \%)$ & $983(18.2 \%)$ & -0.008 & $235(20.1 \%)$ & $233(19.9 \%)$ & -0.004 \\
\hline $\begin{array}{l}\text { Charlson } \\
\text { comorbidity }\end{array}$ & & & & & & 0.023 & & & 0.046 \\
\hline 0 & $1454(25.7 \%)$ & $2220(27.6 \%)$ & $294(25.1 \%)$ & $1397(25.8 \%)$ & $1418(26.2 \%)$ & & $302(25.8 \%)$ & $294(25.1 \%)$ & \\
\hline $1-2$ & $1701(30.0 \%)$ & $2737(34.0 \%)$ & $400(34.2 \%)$ & $1654(30.6 \%)$ & $1680(31.0 \%)$ & & $393(33.6 \%)$ & $400(34.2 \%)$ & \\
\hline $3-6$ & $1179(20.8 \%)$ & $1888(23.4 \%)$ & $269(23.0 \%)$ & $1155(21.3 \%)$ & $1106(20.4 \%)$ & & $284(24.3 \%)$ & $269(23.0 \%)$ & \\
\hline$>6$ & $1329(23.5 \%)$ & $1210(15.0 \%)$ & $206(17.6 \%)$ & $1207(22.3 \%)$ & $1209(22.3 \%)$ & & $190(16.3 \%)$ & $206(17.6 \%)$ & \\
\hline
\end{tabular}

Standardized difference: values $<0.1$ assumed to indicate negligible difference

$P S M$ propensity score matching, MIS minimally invasive surgery, $O S$ open surgery, LS laparoscopy, $R S$ robotic-assisted surgery, Std. diff standardized difference, $P P O$ preferred provider organization, $H M O$ health maintenance organization, $P O S$ point-of-service

Fig. 2 Study flowchart. PSM propensity score matching, $O S$ open surgery, MIS minimally invasive surgery, $L S$ laparoscopic surgery, $R S$ roboticassisted surgery

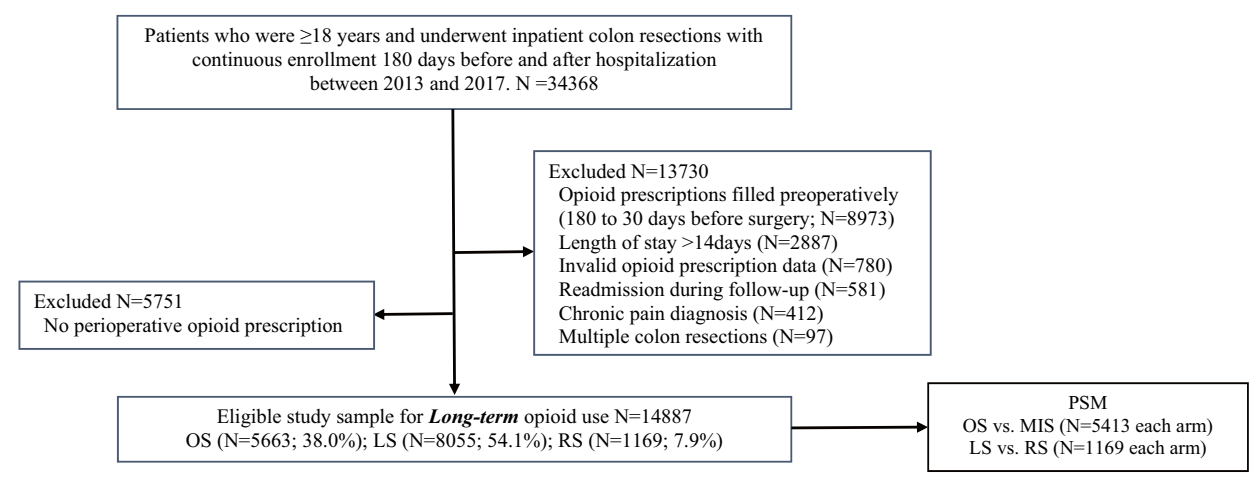

other diagnoses. After PSM, the final analysis consisted of 5,413 matched pairs in the MIS versus OS cohorts and 1169 matched pairs in the RS versus LS cohorts. Baseline sociodemographic and clinical characteristics were comparable in both matched sets (with standardized difference $<0.1$; Table 1).

Among patients filling opioid prescriptions perioperatively, the incidence of long-term opioid use was $15.4 \%$ (2289 patients); $21.0 \%$ in OS, $12.2 \%$ in LS, and $10.9 \%$ in RS. After PSM, MIS significantly decreased long-term prescriptions of 'any opioids' when compared to OS (13.3\% vs. $20.9 \%, p<0.001)$, schedule II/III opioids ( $11.7 \%$ vs. $19.2 \%$, $p<0.001$ ), and high-dose opioids ( $4.3 \%$ vs. $7.7 \%, p<0.001)$ from 90 to 180 days after discharge (Table 2). Among 1169 matched pairs of RS versus LS resections, RS significantly decreased long-term prescriptions of high-dose opioids $(2.1 \%$ vs. $3.8 \%, p=0.015)$, but no significant difference was observed in 'any opioid' use (11.0\% vs. $12.8 \%)$ or schedule II/III opioid use ( $8.9 \%$ vs. $10.3 \%)$.

Subgroup results for long-term opioid prescriptions between patients with malignant and non-malignant diagnoses are shown in Table 2. Among the patients receiving colectomy for non-malignant conditions, those who underwent MIS were less likely to fill long-term opioid prescriptions compared to OS patients in 'any opioids' $(12.1 \%$ vs. $22.0 \%, p<0.001)$, schedule II/III opioids ( $10.4 \%$ vs. $20.4 \%, p<0.001)$ and highdose opioids $(3.9 \%$ vs. $8.3 \%, p<0.001)$ categories. In the RS versus LS comparison, significantly lower rates of longterm opioid prescriptions filled were found in the RS than the LS non-malignant group for 'any opioids' (8.3\% vs. $12.6 \%$, $p=0.012$ ), schedule II/III opioids (6.7 vs. $10.7 \%, p=0.011$ ), and high-dose opioids (1.7\% vs. $4.4 \%, p=0.006)$. MIS patients who had colon resections for colorectal malignancies had lower long-term fill rates of 'any opioids' (15.4\% vs. $18.8 \%$, 
Table 2 Long-term opioid use in propensity score-matched cohorts, stratified by malignant status

\begin{tabular}{|c|c|c|c|c|c|c|}
\hline \multirow[t]{2}{*}{ All patients } & \multicolumn{3}{|c|}{ PSM cohort: OS vs. MIS } & \multicolumn{3}{|c|}{ PSM cohort: LS vs. RS } \\
\hline & OS $(n=5413)$ & MIS $(n=5413)$ & $p$ value & LS $(n=1169)$ & $\mathrm{RS}(n=1169)$ & $p$ value \\
\hline Any opioid use & $1130(20.9)$ & $719(13.3)$ & $<0.001$ & $138(11.8)$ & $127(10.9)$ & 0.473 \\
\hline Schedule II/III opioid use & $1040(19.2)$ & $632(11.7)$ & $<0.001$ & $120(10.3)$ & $104(8.9)$ & 0.261 \\
\hline High-dose opioid use & $414(7.7)$ & $233(4.3)$ & $<0.001$ & $44(3.8)$ & $24(2.1)$ & 0.015 \\
\hline Non-malignant patients & OS $(n=3349)$ & $\operatorname{MIS}(n=3349)$ & $p$ value & $\mathrm{LS}(n=700)$ & $\operatorname{RS}(n=700)$ & $p$ value \\
\hline Any opioid use & $737(22.0)$ & $405(12.1)$ & $<.0001$ & $88(12.6)$ & $58(8.3)$ & 0.012 \\
\hline Schedule II/III opioid use & $682(20.4)$ & $349(10.4)$ & $<.0001$ & $75(10.7)$ & $47(6.7)$ & 0.011 \\
\hline High-dose opioid use & $278(8.3)$ & $131(3.9)$ & $<.0001$ & $31(4.4)$ & $12(1.7)$ & 0.006 \\
\hline Malignant patients & OS $(n=2026)$ & MIS $(n=2026)$ & $p$ value & LS $(n=469)$ & $\mathrm{RS}(n=469)$ & $p$ value \\
\hline Any opioid use & $381(18.8)$ & $311(15.4)$ & 0.004 & $60(12.8)$ & $69(14.7)$ & 0.277 \\
\hline Schedule II/III opioid use & $346(17.1)$ & $276(13.6)$ & 0.002 & $57(12.2)$ & $27(12.2)$ & 0.845 \\
\hline High-dose opioid use & $131(6.5)$ & $102(5.0)$ & 0.051 & $17(3.6)$ & $12(2.6)$ & 0.358 \\
\hline
\end{tabular}

$P S M$, propensity score matching, $O S$ open surgery, MIS minimally invasive surgery, $L S$ laparoscopic surgery, $R S$ robotic-assisted surgery, Schedule II/III Opioid Use controlled substance schedule II or III opioid use

$p=0.004)$, schedule II/III opioids ( $13.6 \%$ vs. $17.1 \%, p=0.002)$ and high-dose opioids $(5.0 \%$ vs. $6.5 \%, p=0.051)$ when compared with OS. There were no significant differences between LS and RS malignant groups in any of the three long-term opioid measures.

Table 3 shows risk factors for long-term 'any opioid' prescription fills. Logistic regression revealed that significant risk factors are non-malignant disease (OR 1.20, 95\% CI $1.06-1.35, p=0.004$ ), tobacco use (OR $1.28,95 \%$ CI 1.14-1.44, $p<0.001$ ), mental health conditions (OR 1.34, 95\% CI 1.20-1.50, $p<0.001$ ), higher Charlson comorbidities score (CCI $>6$ : OR, 2.06, 95\% CI, 1.74-2.43, $p<0.001$ ), and North Central (OR 1.23, 95\% CI 1.03-1.47, $p=0.020$ ), South (OR 1.36, 95\% CI 1.14-1.61, $p=0.001$ ), and West (OR 1.33, $95 \%$ CI $1.10-1.62, p=0.004)$ regions. Conversely, laparoscopic (OR $0.58,95 \%$ CI $0.53-0.64, p<0.001)$ and roboticassisted (OR $0.48,95 \%$ CI $0.40-0.59, p<0.001$ ) approaches, age $>64$ years (OR $0.81,95 \%$ CI $0.68-0.97, p=0.023$ ), and right colectomy (OR $0.61,95 \% \mathrm{CI} 0.43-0.87, p=0.006$ ) were associated with lower risk of long-term opioid use.

Figure 3 demonstrates the filling rates of 'any opioids' by duration of hospital LOS comparing MIS to OS surgical approaches. Longer LOS led to higher long-term opioids fill rates and the trend was found in both OS ( $\geq 7$ days vs. $\leq 3$ days: $27.5 \%$ vs. $12.9 \%)$ and MIS groups ( $\geq 7$ days vs. $\leq 3$ days: $20.7 \%$ vs. $10.1 \%$ ).

\section{Discussion}

Persistent opioid use after surgery is common and patients undergoing colorectal surgery are at higher risk compared to other procedures $[3,15]$. This large database analysis shows that among opioid naïve patients, MIS was associated with a significantly lower risk of opioid filled prescriptions at 90-180 days after colon resection compared with open. Additionally, high-dose long-term opioid filled prescriptions are significantly less for RS than for LS. These differences seem to be most apparent following operations for non-malignant diseases, while patients with cancer show fewer significant differences in opioid use based on surgical approach. Additional risk factors for long-term opioid use include younger age, tobacco and alcohol abuse, mental health conditions, and Charlson comorbidities score $\geq 3$. Patients undergoing right colectomy were less likely to develop long-term opioid use.

Revision of prescribing practices that include opioid reduction strategies have been devised to address the opioid crisis by limiting the amount of unused opioids available for community diversion and decreasing long-term opioid dependence. It is thought that the first opioid prescription to 100 patients results in one heroin user, and almost $75 \%$ of heroin users start with prescription medications as their introduction to opioids [16]. The ability to decrease opioids prescribed at discharge will decrease the amounts of unused opioids available for community diversion. Colorectal surgery is a risk factor for long-term opioid use in opioid-naïve patients [3]. Our study showed that the incidence of long-term opioid use is $13.5 \%$ to $21.2 \%$ and is consistent with other reports $[15,17]$. Though there are several studies evaluating the risk for long-term opioid use for multiple procedures, there are few comparing the MIS and open approaches to colorectal surgery [18-20]. A single institution analysis of 2173 abdominopelvic procedures with intestinal resection revealed that $91 \%$ of patients were discharged on opioids, $4 \%$ were taking opioids 30 days after 
Table 3 Multivariate logistic regression model for long-term opioid use

\begin{tabular}{|c|c|c|c|c|}
\hline \multirow[b]{2}{*}{ Surgical approach } & \multirow[t]{2}{*}{$\begin{array}{l}\text { Adjusted odds } \\
\text { ratio }\end{array}$} & \multicolumn{2}{|c|}{$\begin{array}{l}95 \% \text { confidence } \\
\text { limits }\end{array}$} & \multirow[t]{2}{*}{$p$ value } \\
\hline & & & & \\
\hline Open & Ref & & & \\
\hline Laparoscopic & 0.58 & 0.53 & 0.64 & $<0.001$ \\
\hline Robotic-assisted & 0.48 & 0.40 & 0.59 & $<0.001$ \\
\hline \multicolumn{5}{|l|}{ Age } \\
\hline $18-44$ & Ref & & & \\
\hline $45-54$ & 0.89 & 0.77 & 1.03 & 0.121 \\
\hline $55-64$ & 0.92 & 0.80 & 1.05 & 0.218 \\
\hline Over 64 & 0.81 & 0.68 & 0.97 & 0.023 \\
\hline Male vs. female & 1.01 & 0.92 & 1.11 & 0.788 \\
\hline \multicolumn{5}{|l|}{ Income/year } \\
\hline$<40 \mathrm{k}$ & Ref & & & \\
\hline $40 \mathrm{k}-49 \mathrm{k}$ & 0.87 & 0.74 & 1.01 & 0.073 \\
\hline$>50 \mathrm{k}$ & 0.77 & 0.55 & 1.08 & 0.129 \\
\hline Unknown & 0.98 & 0.77 & 1.25 & 0.867 \\
\hline \multicolumn{5}{|l|}{ Insurance plan } \\
\hline PPO & Ref & & & \\
\hline Comprehensive & 1.05 & 0.89 & 1.25 & 0.541 \\
\hline HMO & 0.95 & 0.81 & 1.12 & 0.559 \\
\hline POS & 1.10 & 0.93 & 1.31 & 0.266 \\
\hline Others & 1.05 & 0.92 & 1.20 & 0.477 \\
\hline Unknown & 0.90 & 0.62 & 1.31 & 0.577 \\
\hline \multicolumn{5}{|l|}{ Metro status } \\
\hline Metropolitan & Ref & & & \\
\hline Non-metropolitan & 1.06 & 0.93 & 1.20 & 0.368 \\
\hline Unknown & 0.74 & 0.30 & 1.80 & 0.506 \\
\hline \multicolumn{5}{|l|}{ Region } \\
\hline Northeast & Ref & & & \\
\hline North central & 1.23 & 1.03 & 1.47 & 0.020 \\
\hline South & 1.36 & 1.14 & 1.61 & 0.001 \\
\hline West & 1.33 & 1.10 & 1.62 & 0.004 \\
\hline Unknown & 1.83 & 0.84 & 4.00 & 0.131 \\
\hline Benign vs. malignant & 1.20 & 1.06 & 1.35 & 0.004 \\
\hline \multicolumn{5}{|l|}{ Procedure type } \\
\hline Sigmoidectomy, yes & 0.91 & 0.65 & 1.28 & 0.601 \\
\hline Left colectomy, yes & 0.98 & 0.70 & 1.36 & 0.895 \\
\hline Right colectomy, yes & 0.61 & 0.43 & 0.87 & 0.006 \\
\hline \multicolumn{5}{|l|}{ Procedure year } \\
\hline 2013 & Ref & & & \\
\hline 2014 & 0.98 & 0.85 & 1.12 & 0.709 \\
\hline 2015 & 0.92 & 0.80 & 1.06 & 0.241 \\
\hline 2016 & 0.90 & 0.78 & 1.04 & 0.145 \\
\hline 2017 & 0.86 & 0.70 & 1.05 & 0.130 \\
\hline Tobacco abuse/history & 1.28 & 1.14 & 1.44 & $<0.001$ \\
\hline Alcohol abuse/depend & 1.31 & 0.98 & 1.74 & 0.068 \\
\hline Mental health cond. & 1.34 & 1.20 & 1.50 & $<0.001$ \\
\hline \multicolumn{5}{|l|}{ Charlson comorbidity } \\
\hline 0 & Ref & & & \\
\hline $1-2$ & 1.03 & 0.91 & 1.17 & 0.627 \\
\hline $3-6$ & 1.15 & 0.99 & 1.35 & 0.072 \\
\hline$>6$ & 2.06 & 1.74 & 2.43 & $<0.001$ \\
\hline
\end{tabular}

Table 3 (continued)

$O S$ open surgery, $L S$ laparoscopy, $R S$ robotic-assisted surgery, $P P O$ preferred provider organization, $H M O$ health maintenance organization, $P O S$ point-of-service

discharge, and $1 \%$ were still on opioids at 90 days. The odds of prolonged opioid use were significantly decreased with the minimally invasive approach compared to open [19]. This study was a single institution analysis in contrast to our large database analysis focused on colectomies. Others have confirmed open surgery as a risk factor for persistent opioid use after gastrointestinal surgery [18]. Our database analysis adds to previous studies by suggesting that the MIS approach to colectomy is an opioid reduction strategy and that the RS approach may be considered where expertise and resources are available, especially for non-malignant diseases.

High-dose opioid prescription fills were less for RS than LS. Subgroup PSM and logistic regression analysis in our study suggests that the significant difference in prescription fills between LS and RS for non-malignant diagnoses is not apparent for malignant conditions. The reasons for the apparent robotic-assisted advantage was not obvious from this analysis. Differences in enhanced recovery protocols and variation in surgeon expertise may be confounding factors. It is also possible that the intracorporeal anastomosis is utilized in a higher percentage of robotic-assisted than laparoscopic colectomies, resulting in less mesenteric traction and shorter incisions with less pain and opioid use [21-23]. The intracorporeal anastomosis is commonly used for roboticassisted right colectomy and may also explain why right colectomy is associated with less long-term opioid use in this study [21, 23].

There is a paucity of literature comparing pain and opioid use in patients undergoing colectomy for malignant versus non-malignant colorectal diseases. One study showed significantly more postoperative opioid use for non-malignant compared to malignant conditions [24]. However, this study is an inpatient opioid use analysis in contrast to our study that is focused on long-term opioid use. Other studies without comparisons to non-malignant conditions have suggested that up to $15 \%$ of patients having oncologic resection develop persistent opioid use [25, 26]. A large, national insurance claims analysis of patients having colectomy for cancer showed that $8-17 \%$ of patients had persistent opioid use, with patients receiving chemotherapy at the higher end of the range [25]. Unlike our study, there was no comparison to a non-malignant group. It may be that patients and prescribers of patients with painful non-malignant diseases like diverticulitis and Crohn's disease have higher opioid expectations after surgery and discharge, thereby contributing to long-term opioid use. Patients with Crohn's disease often receive chronic opioids for abdominal pain though opioid therapy has not been shown to ameliorate chronic pain [27]. 
Fig. 3 Percentages of patients who filled any opioids from 90 to 180 days after discharge by duration of the hospital stay in propensity score-matched cohorts. MIS minimally invasive surgery, $d$ day
$40.0 \%$

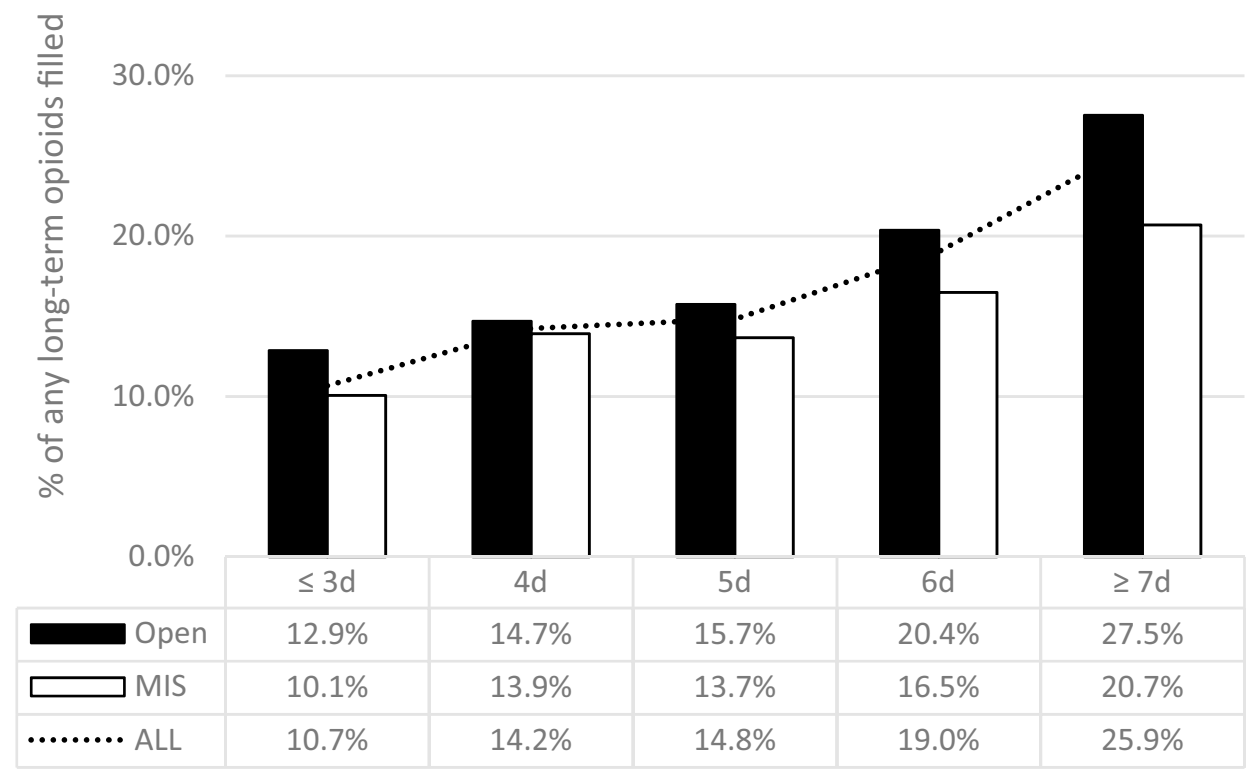

The non-malignant versus malignant colorectal diagnosis differences in long-term opioid use require further study.

Similar to our study, other researchers have identified younger age, tobacco and alcohol abuse, and mental health conditions as risk factors for long-term opioid use [10, 20, 24]. Another large insurance claims database analysis showed that new persistent opioid use $>90$ days after colectomy among opioid-naïve patients was about $10 \%$, and was not due to surgical pain but rather tobacco, alcohol, substance abuse, mood, anxiety, and pain disorders [3]. These investigators included a wide variety of minor and major surgical procedures, while our study was focused on colectomies alone. Others have also described American Society of Anesthesiologists (ASA) Classification and comorbidities as risk factors for long-term opioid use [18, 28].

Sensitivity analysis showed that longer hospital LOS led to higher long-term opioid use rates. There are a couple of possible explanations for this observation. It may be that longer LOS is a proxy for more complications resulting in higher opioid use following discharge. Others have shown that higher inpatient opioid use is associated with postoperative complications and longer LOS [24]. It is also possible that we need to devise more effective strategies weaning patients off opioids as inpatients rather than waiting until after discharge. The longer patients are receiving opioids, the greater is the risk for dependence with one study showing that opioid dependence was significantly associated with prolonged LOS in patients undergoing lumbar fusion [29].

This study is limited by retrospective design that may not account for unknown confounders. Though MIS and RS were associated with less long-term opioid use relative to OS and LS, respectively, causality cannot be inferred. We were unable to control for factors that impact surgical approach choice and other operative decision making. We were unable to control for race/ethnicity because the database does not include that variable. However, we included several predictors not available in many databases such as insurance type and geographic region. Only opioid-naïve patients not taking opioids more than 30 days before surgery were included in this study, because our focus was on comparing MIS and open surgical approaches in the opioid-naïve patient population. Therefore, our results are not generalizable to patients with a history of chronic opioid use. While we included patients receiving opioids within 30 days of surgery defined as opioid naïve based on previous studies, future studies with different definitions may consider this a covariate misclassification. Because about $9-25 \%$ of patients have a history of preoperative opioid use, the long-term opioid use values may have been higher had we included the chronic opioid use patient population [28, 30]. The dataset does not include information on inpatient opioid use, and we were unable to control for enhanced recovery pain management programs that include opioid sparing analgesics, transversus abdominis plane blocks for MIS, epidural analgesia for open colectomies, and other opioid reduction methods in the inpatient setting.

Patients with a hospital stay longer than 14 days were excluded from the analyses, assuming that prolonged LOS is a proxy for emergent or more complicated cases. We wanted our study to be a comparison of relatively uncomplicated operative approaches. If we included patients with hospital stay $>14$ days, our results may have been even 
less favorable for the open complicated cases with longer length of stay. Though our sensitivity analysis showed increase in opioid use with increasing LOS for both open and MIS groups, including 14 days in exclusion criteria may be considered arbitrary. It has been determined that less than $50 \%$ of pain management discharge strategies currently employ non-opioid medications [31]. We were unable to control for patient-reported outcomes like postoperative complications, pain control, and patient satisfaction. This study does not include uninsured or underinsured patients, and our results may not be generalizable to these patient populations. Finally, while prescription claims data may be the best marker available to assess opioid prescriptions readily available in the community as well as long-term medication use (short of contacting patients), the data does not necessarily identify patient adherence.

With the development of better opioid prescribing practices, algorithms, and monitoring schemes, it is important for health care providers to weigh options that increase the effectiveness of opioid reduction and decrease longterm opioid use [32]. Choosing an MIS option and RS for some colorectal operations is a modifiable factor that may contribute to less long-term opioid use [19]. We recognize that patients continue to use opioids long after surgical pain has resolved, that long-term opioid use may not be related to prolonged postoperative pain as much as emotional pain, and that affective distress and post-discharge opioid use is proportional to the quantity prescribed [3,28, 33]. Further research is required to determine the reasons for differences in long-term opioid use among colectomy surgical approaches and how to better manage contributing factors.

\section{Conclusion}

The minimally invasive approach to colon resection for opioid naïve patients is associated with a significant reduction in long-term opioid use when compared to the open approach. Increasing minimally invasive training efforts and adoption may prove to be an opioid reduction strategy. Additionally, the robotic-assisted surgical approach reduced the use of high-dose opioids compared to laparoscopic colectomy and may be an option for non-malignant diseases where resources and expertise are available.

Supplementary Information The online version contains supplementary material available at https://doi.org/10.1007/s00464-021-08338-9.

Funding Access to the MarketScan database and copyediting support was provided by Intuitive Surgical.

\section{Compliance with ethical standards}

Disclosures Dr. Bastawrous has received honoraria from Intuitive Surgical, Inc. for educational speaking. He serves on the advisory board of Medtronic. He has equity interest in Twistle, Inc. Mr. Milky was employed at Intuitive Surgical, Inc during the conduct of the study as summer intern. Dr. Cleary has received honoraria from Intuitive Surgical, Inc. for educational speaking. Drs. Shih and Li are full-time employees of Intuitive Surgical, Inc. Dr. Chang and Dr. Brockhaus have no conflicts of interest or financial ties to disclose.

Open Access This article is licensed under a Creative Commons Attribution 4.0 International License, which permits use, sharing, adaptation, distribution and reproduction in any medium or format, as long as you give appropriate credit to the original author(s) and the source, provide a link to the Creative Commons licence, and indicate if changes were made. The images or other third party material in this article are included in the article's Creative Commons licence, unless indicated otherwise in a credit line to the material. If material is not included in the article's Creative Commons licence and your intended use is not permitted by statutory regulation or exceeds the permitted use, you will need to obtain permission directly from the copyright holder. To view a copy of this licence, visit http://creativecommons.org/licenses/by/4.0/.

\section{References}

1. Scholl L, Seth P, Kariisa M, Wilson N, Baldwin G (2018) Drug and opioid-involved overdose deaths: United States, 2013-2017. MMWR Morb Mortal Wkly Rep 67(5152):1419-1427. https:// doi.org/10.15585/mmwr.mm675152e1

2. Florence CS, Zhou C, Luo F (2013) Xu L (2016) The economic burden of prescription opioid overdose, abuse, and dependence in the United States. Med Care 54(10):901-906. https://doi. org/10.1097/mlr.0000000000000625

3. Brummett CM, Waljee JF, Goesling J, Moser S, Lin P, Englesbe MJ, Bohnert AS, Kheterpal S, Nallamothu BK (2017) New persistent opioid use after minor and major surgical procedures in US adults. JAMA Surg 152(6):e170504-e170504

4. Pacira BioSciences (2018) Exposing a silent gateway to persistent opioid use: a choices matter status report. Pacira BioSciences, Parsippany-Troy Hills, NJ

5. Betcher RE, Chaney JP, Lacy PR, Otey SK, Wood DJ (2013) Analysis of postoperative pain in robotic versus traditional laparoscopic hysterectomy. J Robot Surg 8(1):1-7. https://doi. org/10.1007/s11701-013-0418-z

6. Webster TM, Herrell SD, Chang SS, Cookson MS, Baumgartner RG, Anderson LW, Smith JA Jr (2005) Robotic assisted laparoscopic radical prostatectomy versus retropubic radical prostatectomy: a prospective assessment of postoperative pain. J Urol 174(3):912-914. https://doi.org/10.1097/01.ju.0000169455.25510 .ff

7. Bastawrous AL, Shih I-F, Li Y, Cleary RK (2020) Minimally invasive sigmoidectomy for diverticular disease decreases inpatient opioid use: results of a propensity score-matched study. Am J Surg 220(2):421-427

8. Shkolyar E, Shih I-F, Li Y, Wong JA, Liao JC (2020) Robotassisted radical prostatectomy associated with decreased persistent postoperative opioid use. J Endourol 34(4):475-481

9. IBM Watson Health (2019) IBM MarketScan research databases for health services researchers. IBM Watson Health, Armonk, NY 
10. Clarke H, Soneji N, Ko DT, Yun L, Wijeysundera DN (2014) Rates and risk factors for prolonged opioid use after major surgery: population based cohort study. BMJ 348:g1251

11. Olds C, Spataro E, Li K, Kandathil C, Most SP (2019) Assessment of persistent and prolonged postoperative opioid use among patients undergoing plastic and reconstructive surgery. JAMA Fac Plast Surg 21(4):286-291. https://doi.org/10.1001/jamafacial .2018 .2035

12. Austin PC, Merlo J (2017) Intermediate and advanced topics in multilevel logistic regression analysis. Stat Med 36(20):3257-3277

13. Parsons L (2001) Reducing bias in a propensity score matchedpair sample using greedy matching techniques. In: Proceedings of the twenty-sixth Annual SAS users group international conference 2001. SAS Institute Inc., Cary, NC

14. Nguyen TL, Collins GS, Spence J, Daurès JP, Devereaux PJ, Landais P, Le Manach Y (2017) Double-adjustment in propensity score matching analysis: choosing a threshold for considering residual imbalance. BMC Med Res Methodol 17(1):78. https:// doi.org/10.1186/s12874-017-0338-0

15. Jiang X, Orton M, Feng R, Hossain E, Malhotra NR, Zager EL, Liu R (2017) Chronic opioid usage in surgical patients in a large academic center. Ann Surg 265(4):722-727. https://doi. org/10.1097/SLA.0000000000001780

16. Brat GA, Agniel D, Beam A, Yorkgitis B, Bicket M, Homer M, Fox KP, Knecht DB, McMahill-Walraven CN, Palmer N, Kohane I (2018) Postsurgical prescriptions for opioid naive patients and association with overdose and misuse: retrospective cohort study. BMJ 360:j5790. https://doi.org/10.1136/bmj.j5790

17. Bartels K, Fernandez-Bustamante A, McWilliams SK, Hopfer CJ, Mikulich-Gilbertson SK (2018) Long-term opioid use after inpatient surgery: a retrospective cohort study. Drug Alcohol Depend 187:61-65. https://doi.org/10.1016/j.drugalcdep.2018.02.013

18. Fields AC, Cavallaro PM, Correll DJ, Rubin MS, Sequist T, Khawaja A, Yao Y, Bordeianou LG, Bleday R (2019) Predictors of prolonged opioid use following colectomy. Dis Colon Rectum 62(9):1117-1123. https://doi.org/10.1097/dcr.0000000000001429

19. Stafford C, Francone T, Roberts PL, Ricciardi R (2018) What factors are associated with increased risk for prolonged postoperative opioid usage after colorectal surgery? Surg Endosc 32(8):35573561. https://doi.org/10.1007/s00464-018-6078-3

20. Pitter FT, Sikora M, Lindberg-Larsen M, Pedersen AB, Dahl B, Gehrchen M (2020) Use of opioids and other analgesics before and after primary surgery for adult spinal deformity: a 10-year nationwide study. Neurospine 17(1):237-245. https://doi. org/10.14245/ns.1938106.053

21. Akram WM, Al-Natour RH, Albright J, Wu J, Ferraro J, Shanker BA, McClure AM, Cleary RK (2018) A propensity score-matched comparison of intracorporeal and extracorporeal techniques for robotic-assisted right colectomy in an enhanced recovery pathway. Am J Surg 216(6):1095-1100. https://doi.org/10.1016/j.amjsu rg.2018.06.010

22. Al Natour RH, Obias V, Albright J, Wu J, Ferraro J, Akram WM, McClure AM, Shanker BA, Cleary RK (2019) A propensity score matched comparison of intracorporeal and extracorporeal techniques for robotic-assisted sigmoidectomy in an enhanced recovery pathway. J Robot Surg 13(5):649-656. https://doi.org/10.1007/ s11701-018-00910-1

23. Brown RF, Brockhaus KK, Rajkumar D, Battaglia M, Cleary RK (2021) Postoperative pain and opioid use after enhanced recovery pathway robotic colon and rectal surgery: does specimen extraction site matter? Dis Colon Rectum. https://doi.org/10.1097/ DCR.0000000000001868

24. Yap R, Nassif G, Hwang G, Mendez A, Erkan A, Kelly J, Debeche-Adams T, Albert M, Monson J (2020) Achieving opioid-free major colorectal surgery: is it possible? Dig Surg. https://doi. org/10.1159/000505516

25. Lee JS, Hu HM, Edelman AL, Brummett CM, Englesbe MJ, Waljee JF, Smerage JB, Griggs JJ, Nathan H, Jeruss JS, Dossett LA (2017) New persistent opioid use among patients with cancer after curative-intent surgery. J Clin Oncol 35(36):4042-4049. https://doi.org/10.1200/jco.2017.74.1363

26. Lillemoe HA, Newhook TE, Vreeland TJ, Arvide EM, Dewhurst WL, Grubbs EG, Aloia TA, Vauthey JN, Lee JE, Tzeng CD (2019) Educating surgical oncology providers on perioperative opioid use: results of a departmental survey on perceptions of opioid needs and prescribing habits. Ann Surg Oncol 26(7):2011-2018. https://doi.org/10.1245/s10434-019-07321-y

27. Coates MD, Seth N, Clarke K, Abdul-Baki H, Mahoney N, Walter V, Regueiro MD, Ramos-Rivers C, Koutroubakis IE, Bielefeldt K, Binion DG (2020) Opioid analgesics do not improve abdominal pain or quality of life in Crohn's disease. Dig Dis Sci 65(8):23792387. https://doi.org/10.1007/s10620-019-05968-x

28. Howard R, Vu J, Lee J, Brummett C, Englesbe M, Waljee J (2020) A pathway for developing postoperative opioid prescribing best practices. Ann Surg 271(1):86-93. https://doi.org/10.1097/ SLA.0000000000003434

29. Tank A, Hobbs J, Ramos E, Rubin DS (2018) Opioid dependence and prolonged length of stay in lumbar fusion: a retrospective study utilizing the national inpatient sample 2003-2014. Spine 43(24):1739-1745. https://doi.org/10.1097/BRS.0000000000 002714

30. Keller DS, Zhang J, Chand M (2019) Opioid-free colorectal surgery: a method to improve patient \& financial outcomes in surgery. Surg Endosc 33(6):1959-1966. https://doi.org/10.1007/ s00464-018-6477-5

31. Bartels K, Mahoney K, Raymond KM, McWilliams SK, Fernandez-Bustamante A, Schulick R, Hopfer CJ, Mikulich-Gilbertson SK (2020) Opioid and non-opioid utilization at home following gastrointestinal procedures: a prospective cohort study. Surg Endosc 34(1):304-311. https://doi.org/10.1007/s00464-01906767-1

32. Hah JM, Bateman BT, Ratliff J, Curtin C, Sun E (2017) Chronic opioid use after surgery: implications for perioperative management in the face of the opioid epidemic. Anesth Analg 125(5):1733-1740. https://doi.org/10.1213/ane.000000000000245 8

33. Waljee JF, Li L, Brummett CM, Englesbe MJ (2017) Iatrogenic opioid dependence in the United States: are surgeons the gatekeepers? Ann Surg 265(4):728-730. https://doi.org/10.1097/ SLA.0000000000001904

Publisher's Note Springer Nature remains neutral with regard to jurisdictional claims in published maps and institutional affiliations. 